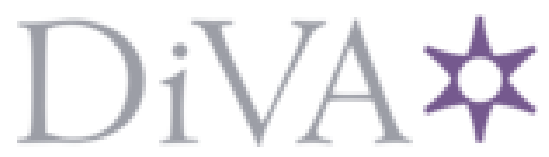

http://www.diva-portal.org

This is the published version of a paper published in Vård $i$ Norden.

Citation for the original published paper (version of record):

Magnusson, C., Ekebergh, M., Jutengren, G., Knutsson, S. (2014)

Patientnärmre vård: En observationsstudie av sjuksköterskans tid för patientnära vård.

Vård i Norden, 34(4): 4-9

Access to the published version may require subscription.

N.B. When citing this work, cite the original published paper.

Permanent link to this version:

http://urn.kb.se/resolve?urn=urn:nbn:se:hj:diva-25655 


\title{
Patientnärmre vaird:
}

\section{En observationsstudie av sjuksköterskans tid för patientnära vaird}

\author{
Carl Magnusson, RN, BScN, Margaretha Ekebergh, RN, Professor, Göran Jutengren, PhD in Psychology, Susanne Knutsson, RN, \\ BSc in Nursing and Intensive Care, PhD
}

\section{PATIENTFOCUSED CARE: AN OBSERVATIONAL STUDY OF REGISTERED NURSES'TIME FOR DIRECT PATIENT CARE}

\begin{abstract}
The aim: To conduct a follow up study to measure registered nurses' time of direct patientcare after implementation of patientfocused care (PFC).

Background: PFC is an organizational model with the objective to increase both patient participation and health care effectiveness. After a reconstruction of wards to single bedrooms in a hospital south of Sweden. PFC was implemented to increase time for direct patientcare in order to better meet patients'needs.

Method: Time measured observations were conducted. 20 registered nurses were observed in four different wards at a 525-bed hospital in south of Sweden after implementation of PFC.

Findings: In a workday of 8,5 hrs, registered nurses spend 6,8 hrs (79,8\%) with work related to patients. Time for directcare was 2 hrs $(23,8 \%)$ and time for indirect care was $4,8 \mathrm{hrs}(56 \%)$. Indirect care consists of categories such as documentation, report and medical round. Conclusion: In comparison before implementation of PFC, time for patientrelated care increased by 10,8\%. However, time is spent mainly at patient indirectcare activities. It is important to also focus on a change of culture in the organization to succeed with an implementation of PFC.
\end{abstract}

KEY WORDS: Patientfocused care, Patientrelated care, Patient participation, Working hours

\section{INTRODUKTION}

En god vård kännetecknas av helhetssyn och ett patientperspektiv. För att kunna utföra en sådan vård behöver sjuksköterskan tid för att möta patienten och vara öppen för patientens perspektiv (1). Patientnärmre vård (PNV) som modell för ett förändringsarbete av den traditionella vårdstrukturen kan bidra till att sjuksköterskan får mer tid att vara nära och möta patientens behov. Ur ett svenskt perspektiv saknas det kunskap om vilken inverkan en implementering av PNV har på sjuksköterskans patientnära tid. Den här studien avsåg mäta den tid som sjuksköterskan har till sitt förfogande för patientnära arbete och hur den fördelas efter implementering av PNV på vårdavdelning. Studien är en uppföljning av tidigare studie (delstudie 1 (2)).

\section{BAKGRUND}

PNV etablerades som modell för förbättringsarbete och ökad effektivitet redan för 50 år sedan i USA. Utvecklingen av PNV har dock tvingats stå tillbaka för den traditionella vården som till sin natur varit mer teknik och sjukdomsorienterad (3). PNV baseras på Total Quality Management (TQM) med bakgrund i industrin och som har varit ett koncept för framgång bland annat hos Toyota. TQM handlar om att alltid sträva efter att förbättra verksamheten. Det innebär bl.a. att all personal ska bidra till den kontinuerliga utvecklingen av verksamheten och att kundens direkta och indirekta önskemål tillgodoses samt att ledare i organisationen är engagerade och närvarande (4). Först under slutet av 80-talet implementerades PNV på det första sjukhuset i USA (5).

Det saknas en vedertagen definition av PNV och vilka komponenter som ingår (6-9). Hur PNV implementeras är beroende på vilken typ av vårdgivare som avser införa modellen. Vanligt är att PNV införs som organisationsmodell för att främja en närmre kontakt med patienten (5). Enligt Inde (10) bygger en implementering av PNV på ett processinriktat förändringsarbete inom fem områden: Närvarande ledarskap, välfungerande arbetsteam, en organisation i utveckling, innovativt arbetsklimat och en levande värdegrund. Mang (11) identifierar sex områden som PNVs målsättning: Samlokalisering av patientgrupper med liknande behov, decentralisering av tjänster som patienten är $\mathrm{i}$ behov av för att minska förflyttning i sjukhuset, ökad kompetens hos personalen $\mathrm{i}$ vårdteamet för att öka kontinuiteten och effektiviteten, multidisciplinära team som tillsammans möter patientens behov och ansvarar för patienten, ökad patientdelaktighet och självbestämmande, planering och rationalisering av uppgifter för ökad effektivitet.

Den traditionella organisatoriska strukturen i vården bidrar till en vård som utgår från professionens behov istället för patientens. Patienten vårdas vid olika instanser och avdelningar, vilket medför att helhetsbilden kring patienten minskar eller helt uteblir (12). En implementering av PNV är ett strategiskt beslut och innebär en förändringsprocess där verksamheten hela tiden arbetar mot PNV. För att leverera vård av högre kvalitet till en lägre kostnad måste organisationen omstruktureras (13). Varje steg i verksamhetens förändringsarbete mot PNV ska fokusera på ökad patientnytta (14). Förutsättningen för en framgångsrik implementering av PNV innebär därmed en förändring av kulturen i verksamheten (12).

Internationellt sett har låg patienttillfredsställelse varit en orsak till implementering av PNV. En ökad patienttillfredsställelse är ett mått på patientens upplevelse av vårdkvalité (15). Tidigare studier visar att patienten föredrar vårdmöten som baseras på PNV (3). Skillnader i total patientupplevelse/patientnöjdhet efter implementering av PNV har dock inte påvisats $(16,17)$. Sjuksköterskors upplevelse av att arbeta med PNV är positiva och PNV ökade tillfredställelsen i arbetet $(5,16,18)$. Hälften av sjuksköterskorna upplevde att de hade mer tid för patienterna efter implementering av PNV (5).

Mötet med patienten och patientens berättelse ger indikationer för sjuksköterskan om patientens behov och upplevelse (19). Sjuksköterskan måste ha tid för att kunna bemöta patientens svar och skapa en god vårdrelation som främjar hälsa. Patientens berättelse och en förståelse för patientens situation är essensen i sjuksköterskans arbete 


\section{Tabell 1. Fördelning av sjuksköterskans arbetstid innan implementering av PNV}

\section{Fördelning total tid av sjuksköterskans arbetspass}

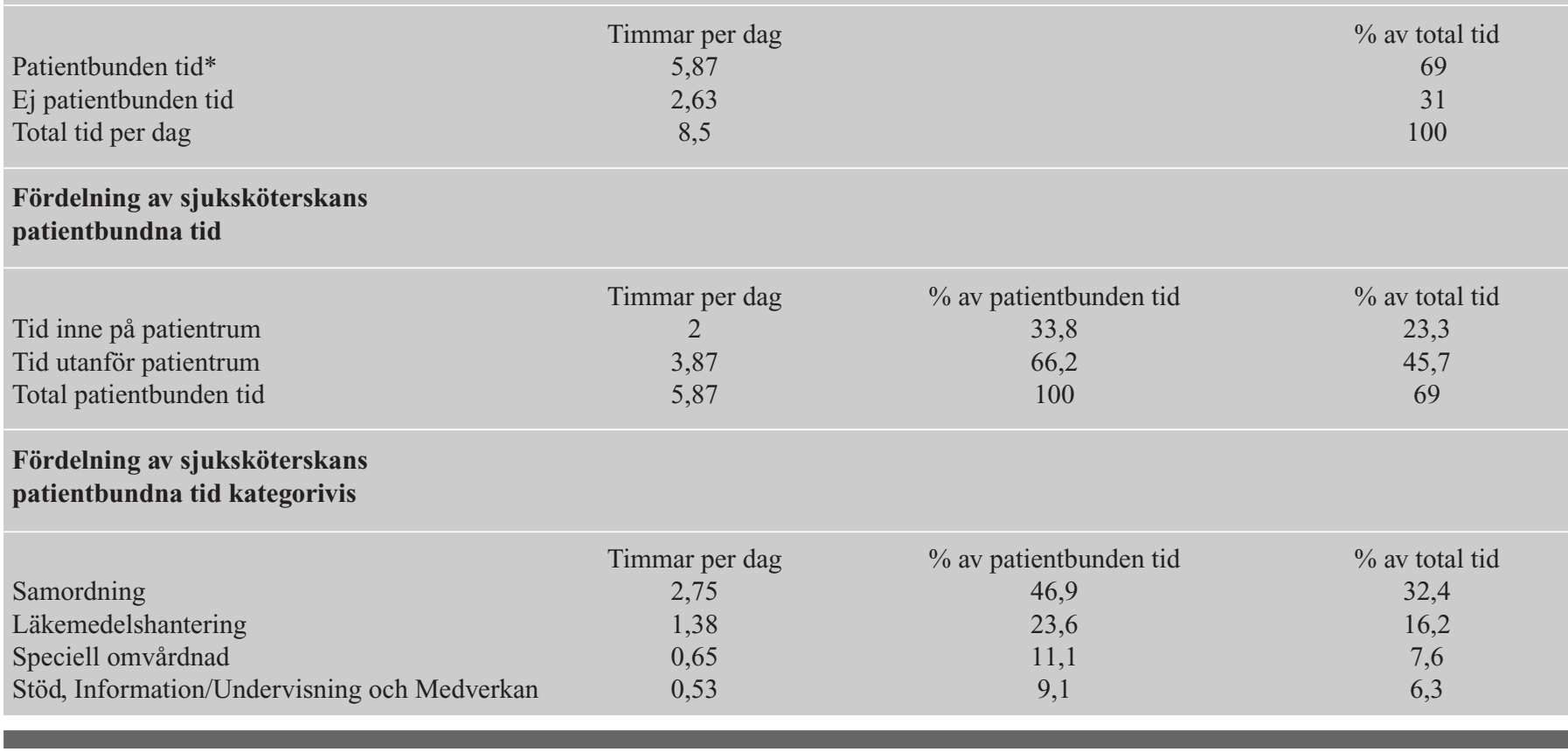

* Patientbundet arbete innefattar all typ av arbete som kan relateras till en specifik patient.

(1). Utvecklingen av den traditionella vården har dock medfört att en hög andel av sjuksköterskans tid utgörs av administrativa arbetsuppgifter. En sjuksköterska ägnar under sitt arbetspass i genomsnitt $35 \%$ av tiden för dokumentation och administration $(12,20)$. På ett mellanstort sjukhus i södra Sverige genomfördes en studie på fyra vårdavdelningar, där data samlades in om sjuksköterskans patientnära tid innan implementering av PNV (delstudie 1 (2)). Av den totala arbetstiden $(8,5 \mathrm{tim} / \mathrm{dag})$ utgjorde patientbundet arbete i genomsnitt 5,87 tim/dag (Tabell 1, delstudie 1 (2)).

Ledordet för PNV är att all vård ska ske med patienten i fokus, vilket i sin tur kan bidra till att patienten upplever en ökad delaktighet $i$ sin vård. Syftet med PNV är att skapa förutsättningar för sjuksköterskan att få mer tid hos patienten. Tidigare studier är inte samstämmiga om PNVs effekter och är delvis baserade på annan organisering av sjukvården än den svenska. Det är därför av intresse att studera hur mycket tid som sjuksköterskan har till sitt förfogande för patientnära arbete efter implementering av PNV enligt svenska förhållanden.

\section{SYFTE}

Syftet är att undersöka hur sjuksköterskan disponerar sin tid i det patientnära arbetet efter implementering av PNV.

\section{METOD}

\section{Design}

Studien utgår ifrån en icke experimentell kvantitativ deskriptiv design, där materialet analyserats med beskrivande och jämförande statistik. Genom observationer registrerades tid för sjuksköterskans olika arbetsmoment under ett arbetspass. En beskrivande undersökningsmetod användes eftersom intentionen var att observera, beskriva och dokumentera, d.v.s. skildra karaktäristika av personer, situationer och frekvenser av dessa (21).

\section{Organisation}

Studien genomfördes på ett mellanstort sjukhus i södra Sverige där fyra vårdavdelningar hade flyttat in i nya lokaler och PNV implemen- terats. Avdelningarna bestod av tre moduler med enkelrum i syfte att öka integriteten samt bidra till ökad patientdelaktighet. I varje modul vårdades sju patienter av ett tvärprofessionellt team. Traditionell sjuksköterskeexpedition hade ersatts av mindre arbetsstationer i varje modul och ett rum för rond med storbildsskärm. Läkaren kom till modulen och rond genomfördes enbart med patienterna i modulen. Syftet var att skapa tidsvinster för sjuksköterskan samt att hon/han hela tiden var närvarande i modulen. En reception fanns lokaliserad centralt på avdelningen som hanterade telefonsamtal, administrativa uppgifter och därmed avlastade respektive modul. Läkemedel beställdes centralt på sjukhuset när patienten blev inlagd och levererades dosdispenserade, vilket medförde att sjuksköterskan inte behövde dela läkemedel som tidigare. Tanken var även att mottagningar tillhörande respektive specialitet skulle samlokaliseras inne på avdelningen där personalen bemannade både avdelning och mottagning för att öka kontinuiteten $\mathrm{i}$ vården för patienten. Målsättningen med sjukhusets implementering av PNV var att öka vårdkvalitén och patientsäkerheten, minska upplevelsen av stress hos vårdpersonalen samt öka fokus på teamarbete.

\section{Urval}

20 sjuksköterskor inbjöds till att delta i studien. Inklusionskriterier var att avdelningen flyttat till nya lokaler och i och med det infört PNV samt att utbildade sjuksköterskor med minst ett års erfarenhet av avdelningsarbetet på den bestämda avdelningen skulle delta. Deltagarna valdes ut av respektive avdelnings enhetschef p.g.a. strukturella och verksamhetsmässiga skäl.

\section{Datainsamling och genomförande}

Studien beviljades av omvårdnadschefen på sjukhuset och ingick i ett större projekt tillsammans med delstudie 1 (2). Informationsbrev om studien till berörda sjuksköterskor och chefer delgavs personligen vid projektets start. De sjuksköterskor som var aktuella att delta i studien blev informerade om dess syfte av respektive enhetschef på avdelningen och av observatörerna när studien inleddes. Totalt observerades 20 sjuksköterskor, 16 kvinnor och fyra män. En sjuksköterska observerades per dag och totalt fem sjuksköterskor observerades per 


\begin{tabular}{lcc} 
Tabell 2. Fördelning av total tid av sjuksköterskans arbetspass för alla avdelningar \\
\hline \\
Patientbunden tid & Timmar per dag & $\%$ av hela arbetsdagen \\
Ej patientbunden tid & 6,8 & 79,8 \\
Total tid per dag & 1,7 & 20,2 \\
\end{tabular}

\section{Tabell 3. Fördelning av sjuksköterskans patientbundna tid, antal timmar per dag}

$\begin{array}{lccc} & \text { Timmar per dag } & \% \text { av patientbunden tid } & \% \text { av hela arbetsdagen } \\ \text { På patientrum } & 2 & 29,8 & 23,8 \\ \text { Utanför patientrum } & 4,8 & 70,2 & 56,0 \\ \text { Total patientbunden tid } & 6,8 & 100 & 79,8\end{array}$

\begin{tabular}{|c|c|c|c|c|}
\hline Kategorier & $\begin{array}{l}\text { medelvärde (\% av } \\
\text { patientbunden tid) }\end{array}$ & $\begin{array}{c}\text { medelvärde } \\
\text { inne på rummet }(\%)^{*}\end{array}$ & $\begin{array}{c}\text { medelvärde } \\
\text { utanför rummet }(\%)^{*}\end{array}$ & $\begin{array}{l}\% \text { av hela } \\
\text { arbetsdagen }\end{array}$ \\
\hline Samordning & $4(58,8)$ & $0,25(6)$ & $3,75(94)$ & 46,9 \\
\hline Läkemedelshantering & $1,15(16,3)$ & $0,4(35)$ & $0,75(65)$ & 13 \\
\hline Speciell omvårdnad & $0,42(6,2)$ & $0,34(81)$ & $0,08(19)$ & 4,9 \\
\hline $\begin{array}{l}\text { Stöd, Information/ } \\
\text { Undervisning och Medverkan }\end{array}$ & $0,64(9,5)$ & $0,56(87,5)$ & $0,08(12,5)$ & 7,6 \\
\hline
\end{tabular}

*\% av den aktuella kategorin

avdelning. En sjuksköterska observerades två gånger, beroende på att den sjuksköterska som skulle delta i studien den aktuella dagen hade rollen som koordinator vilket innebar ett arbete utan patientkontakt. En sjuksköterska avböjde att delta varvid en annan sjuksköterska frivilligt erbjöd sig att bli observerad. Observationerna pågick under sex veckor i augusti och september 2011. Sjuksköterskans arbetspass omfattade i genomsnitt 8,5 timmar. För att säkerställa validitet har flera avdelningar jämförts. Jämförelserna har varit samtida och observationer har genomförts på de avdelningar som observerades i delstudie 1. Antalet observatörer har varit två för att minimera systematiska fel vid datainsamlingen och för att minska påverkansfaktorerna (21). Inför studien skapades ett nytt instrument för att på ett strukturerat och tillförlitligt sätt notera observerad tid. Instrumentet utformades efter VIPS-modellen (22) och utgick från samma kategorier som i delstudie 1 (2). Instrumentet indelades i tre övergripande grupper: patientbundet arbete på patientrum, patientbundet arbete utanför patientrum samt icke patientbundet arbete. Genom kontinuerliga observationer av sjuksköterskans arbete registrerades tid för varje aktivitet. Varje enskild aktivitet avrundades till hela minuter. Instrumentet testades inledningsvis av observatörerna på avdelningar oberoende av varandra och avstämning gjordes avseende hur kategorierna hade tolkats. Enighet fanns kring 34 kategorier och för fyra kategorier fanns en oenighet, vilket gav en reliabilitetskoefficient på 0,89 (34/34+4). Enligt Polit och Beck (21) anses det vara acceptabelt. Innehållsvaliditeten av ett instrument är baserat på omdöme när det skapas. I den här studien baserades instrumentet på tidigare studier om sjuksköterskan arbetsuppgifter (22) och författarnas tidigare erfarenheter om hur sjuksköterskans arbete bedrivs på vårdavdelning. Innehållsvaliditet anses därmed vara nådd.

\section{Dataanalys}

Data har analyserats med hjälp av deskriptiv och jämförande statistik (21). Ett frekvenshistogram visar antalet frekvenser per kategori, d.v.s. antalet observerade minuter för ett specifikt arbetsmoment under sjuksköterskans arbetspass. Medelvärden har beräknats genom summan av antalet minuter på de fyra avdelningarna tillsammans, både övergripande och kategorivis. En ANOVA (Analysis of variance) genomfördes för att statistiskt säkerställa om det finns skillnader i sjuksköterskans tid mellan avdelningarna. Om indikation för signifikans förelåg användes Tukeys' HSD (Honestly Significant Difference) test för signifikans (23). Vid alfa $=0,05$ säkerställs signifikans på fvärden över 3,239 (24).

\section{Etiska överväganden}

De sjuksköterskor vars arbete har observerats blev informerade om studiens syfte av respektive enhetschef och av observatörerna när studien inleddes. Sjuksköterskorna deltog frivilligt och kunde närhelst de önskade avbryta deltagandet. All data har behandlats konfidentiellt och det framgår inte vem som observerats eller vilken avdelning. Observatörerna har följt sjuksköterskan i sitt arbete, vilket inneburit observation inne på patientrum. Observatören har informerat patienten om studiens syfte och frågat om tillåtelse att observera. I vissa fall har det inte varit lämpligt med hänsyn till att bevara patientens integritet. Vid dessa situationer fördes en dialog med sjuksköterskan i efterhand om vilka moment som genomfördes under den uppmätta tiden.

\section{RESULTAT}

Fördelning av sjuksköterskans patientbundna arbetstid

Efter implementering av PNV visar medelvärdet för de fyra vårdavdelningarna tillsammans att sjuksköterskan arbetade med patientbundet arbete $6,8(\mathrm{SD}=0,44) \mathrm{tim} / \mathrm{dag}$. Andelen patientbundet arbete under ett arbetspass var 79,8\% av den totala arbetstiden. Patientbundet arbete innefattar allt arbete som sjuksköterskan utför både utanför och på patientrum som kan knytas till en specifik patient. Medelvärdet för arbete som inte var patientbundet uppgick till 1,7 $(\mathrm{SD}=0,84)$ tim/dag, vilket utgör en andel på 20,2 \% av den totala arbetstiden. I arbetet som inte var patientbundet ingick tid för rast, möte, planering av schema och annat avdelningsarbete (Tabell 2.).

Tid som uppmättes som patientbunden tid utanför patientrum uppgick till 4,75 $(\mathrm{SD}=0,36)$ tim/dag och utgör $56 \%$ av den totala arbetstiden samt 70,2 \% av den patientbundna tiden. Exempel på arbetsuppgifter utanför patientrum är rond, rapport, dokumentation och arbete 
av administrativ karaktär. Medelvärdet för sjuksköterskans patientnära arbete inne på patientrum uppgick till $2(\mathrm{SD}=0,19)$ tim/dag och utgör $23,8 \%$ av den totala arbetstiden. Tiden innefattade främst omvårdnadshandlingar såsom behandling, provtagning, undersökningar men även handlingar där kommunikation med patienten var centralt som tröst, stöd, information och undervisning. Av den patientbundna tiden var andelen tid inne på patientrum 29,8 \% (Tabell 3.).

\section{Fördelning av sjuksköterskans patientbundna tid kategorivis}

Resultatet per kategori visar att Samordning och Läkemedelshantering upptog en stor del av sjuksköterskans arbetstid (Tabell 4.).

Sjuksköterskan utförde aktiviteter av samordnande karaktär i genomsnitt $4(\mathrm{SD}=0.96)$ tim/dag. Medelvärdet för Samordning utanför patientrum uppgick till $3,74(\mathrm{SD}=0,79)$ tim/dag och utgjordes av rond, rapport, dokumentation, journalläsning samt administrativt arbete. Medelvärdet för Samordning på patientrum uppgick till $0,26(\mathrm{SD}=$ $0,31)$ tim/dag och utgjordes främst av läkarrond. De mest tidskrävande aktiviteterna i kategorin Samordning var administration och rapport. Medelvärdet för aktiviteten administration var 1,2 $(\mathrm{SD}=0,43)$ tim/dag och rapport $1(\mathrm{SD}=0,15)$ tim/dag. Rapport definierades som både läs och muntlig rapport och tog plats utanför patientrum. Administration och rapport utgjorde tillsammans $26,1 \%$ av den totala arbetstiden och $32,7 \%$ av den patientbundna tiden. Även dokumentation utgjorde en stor del av tiden i kategorin Samordning. Medelvärdet för dokumentation uppgick till $0,84(\mathrm{SD}=0,43)$ tim/dag och en andel på $9,9 \%$ av den totala arbetstiden samt $12,4 \%$ av den patientbundna tiden.

I kategorin Läkemedelshantering ingick iordningställande av läkemedel som i stort sett alltid tog plats utanför patientrum. Andra aktiviteter som registrerades i kategorin var administrering och överlämning av läkemedel i huvudsak inne på patientrum. Medelvärdet av den totala tiden för Läkemedelshantering uppgick till $1,15(\mathrm{SD}=0,51)$ tim/dag och bestod i $0,75(\mathrm{SD}=0,37)$ tim/dag utanför patientrum och $0,4(\mathrm{SD}=0,22) \mathrm{tim} / \mathrm{dag}$ inne på patientrum. Av sjuksköterskans totala tid under arbetspasset utgjorde Läkemedelshantering $13 \%$ och av den patientbundna tiden var andelen 16,3\%.

Kategorin Speciell omvårdnad utgjorde en mindre del av sjuksköterskans patientbundna tid jämfört med Samordning. I kategorin ingick aktiviteter som provtagningar, undersökningar, anläggning av perifera infarter samt pre- postoperativa åtgärder. Medelvärdet uppgick till $0,42(\mathrm{SD}=0,35) \mathrm{tim} / \mathrm{dag}$. Av den tiden var $0,08(\mathrm{SD}=0,08)$ tim/dag utanför patientrum och $0,34(\mathrm{SD}=0,28)$ tim/dag på patientrum. Speciell omvårdnad utgjorde $4,9 \%$ av sjuksköterskans totala arbetstid och $6,2 \%$ av den patientbundna tiden. Speciell omvårdnad utanför patientrum utgjordes främst av aktiviteter som bestod $i$ att förbereda material inför undersökningar eller analysering av prover efter provtagning.

De kategorier som var av betydelse för sjuksköterskans kommunikation med patienten utgjordes av Stöd, Information/Undervisning och Medverkan. Aktiviteter som ingick i dessa kategorier var kontakt med närstående, tröst och stöd, information, undervisning, kommunikation och telefonrådgivning. Medelvärdet för kategorierna var tillsammans $0,64(\mathrm{SD}=0,26) \mathrm{tim} / \mathrm{dag}$. Av den tiden tog möten med patient eller anhöriga plats utanför patientrum under $0,08(\mathrm{SD}=0,08)$ tim/dag och $0,56(\mathrm{SD}=0,25)$ tim/dag utgjordes av möten inne på patientrum. Andel av den totala arbetstiden var 7,6 \% och av den patientbundna tiden var andelen $9,5 \%$.

\section{Variansanalys mellan avdelningar}

Vid jämförelser mellan avdelningarna avseende den totala tiden som utgjordes av patientbunden tid och icke patientbunden tid kunde inte en signifikant differens påvisas $(\mathrm{F}=1,45, \mathrm{p}=0,26)$. För tid som utgjordes av patientbunden tid inne på patientrum $(\mathrm{F}=0,65, \mathrm{p}=0,59)$ respektive patientbunden tid utanför patientrum $(\mathrm{F}=1,28, \mathrm{p}=0,31)$ kunde inte en statistiskt säkerställd differens påvisas mellan avdelningarna.

\section{DISKUSSION}

Resultatet av denna studie visar att efter implementering av PNV utgjordes sjuksköterskans arbetsdag av 79,8\% patientbunden tid.
Patientkontakt inne på patientrum utgjorde 23,8 \%, vilket innebär att den patientbundna tiden till största del består av arbete utanför patientrum utan direktkontakt med patienten. Samordning och Läkemedelshantering stod för den största andelen med $46,9 \%$ respektive $13 \%$ av sjuksköterskans totala arbetstid. De kategorier som kunde relateras till en direktkontakt med patienten, såsom Speciell omvårdnad samt Stöd, information och medverkan utgjorde 4,9\% respektive 7,6 \% av sjuksköterskans totala arbetstid.

Att sjuksköterskan tillbringar liten del av sin tid inne på patientrummet, i jämförelse med den patientbundna tiden utanför, kan bero på att tiden är styrd av åtgärder, där de uppgifter som utförs inne på patientrummet först måste ha initierats av en åtgärd. Det ger minskade möjligheter för sjuksköterskan att lära känna patienten och identifiera dennes behov som kanske inte alltid uttrycks eller kan uttryckas med ord. Genom att basera sitt arbete på givna rutiner kan sjuksköterskan skapa ett skydd för att undgå svåra situationer samt för att möta patienters lidande (25). Rutinen i sig är en aktivitet som måste utföras och det finns motiv för att utföra den men att vara styrd av rutiner kan bidra till att patienten inte blir sedd (1), vilket minskar förutsättningarna för patientens delaktighet $i$ sin vård. Risken för att patienten inte blir sedd kan öka i samband med införande av enkelrum där patienten blir mer isolerad än tidigare.

I jämförelse med delstudie 1, dvs. innan PNV implementerades på vårdavdelningarna, ökade sjuksköterskans totala tid för arbete relaterat till patient med i genomsnitt 10,8 \%, från $69 \%$ till 79,8 \% (2). Den tid som utgjordes av patientbundet arbete inne på patientrum var relativt oförändrad med en genomsnittlig ökning på $0,5 \%$ från $23,3 \%$ till $23,8 \%$. Andel tid inne på patientrum i denna studie är låg i förhållande till tidigare studier (26-28) om sjuksköterskans arbetstid, vilka visar på att andelen för patientnära vård utgörs av 30-38\%. Resultatet talar för att sjuksköterskan efter implementering av PNV har fått mer tid till förfogande för att utföra patientnära arbete. Dock indikerar den här studien att den vunna tiden spenderas på patientbundet arbete utanför patientrum. Att sjuksköterskan utför patientbundna arbetsuppgifter utanför patientrum i så stor utsträckning kan bero på sjuksköterskans centrala roll i det multidisciplinära teamet (26) med ansvar för helhetsbilden runt patienten.

Det innefattar bl.a. samverkan med läkare, sjukgymnast och arbetsterapeut. Sjuksköterskan ansvarar även för kontakt med externa enheter såsom hemsjukvård eller särskilt boende för att informera om patientens behov efter vårdvistelsen på avdelningen. Det är aktiviteter som tar tid i anspråk för sjuksköterskan och som sker utöver det direkta patientnära arbetet, vilket även kan ske på bekostnad av det patientnära arbetet. Om arbetsuppgifter relaterade till patientbundet arbete utanför patientrum prioriteras kan det medföra en minskad möjlighet för patienten att uppleva delaktighet $\mathrm{i}$ sin vårdsituation. Mindre tid för sjuksköterskan att etablera en vårdrelation med patienten kan också medföra att vården decimeras till enbart utförande av specifika vårdhandlingar (1).

Vid en mer detaljerad jämförelse av de kategorier som utgjordes av patientrelaterad tid var Samordning den kategori som upptog den största andelen tid. Samordning innefattade aktiviteter som huvudsakligen tog plats utanför patientrum. Av sjuksköterskans totala arbetstid utgjorde Samordning en andel på 46,9 \%. I delstudie 1 utgjorde Samordning $32,4 \%$ av den totala arbetstiden (2). Efter implementering av PNV ökade tiden med 14,5\%. Vinsten i tid som en implementering av PNV medför, hamnar till stor del i den kategori som innefattar administration, dokumentation, rond och rapport. Det finns således en potential att omfördela tiden till patientnära tid för att därigenom öka patientens delaktighet. Ökad delaktighet kan nås genom att mer tydligt arbeta med ett patientperspektiv där vårdande aktiviteter utgår ifrån patientens berättelse (1) samt att integrera aktiviteter av samordnande karaktär med patienten i större utsträckning.

Den andra kategorin som upptog den största delen av sjuksköterskans patientbundna tid var Läkemedelshantering som utgjorde $13 \%$ av den totala arbetstiden. En stor del av sjuksköterskans uppdrag i vården innefattar hantering och administrering av ordinerade läkemedel på ett patientsäkert sätt. För att bidra till ökad patientsäkerhet kan administrering av läkemedel ske inne på patientrum och på det sättet

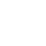


bidra till att patienten blir mer delaktig. Efter implementering av PNV infördes ett system med dispenserade läkemedel som expedierades till avdelningen, vilket i sig kan bidra till ökad patientsäkerhet samt leda till minskad tid vid iordningsställande av läkemedel. I jämförelse med delstudie 1 minskade tiden för läkemedelshantering efter implementering av PNV med 3,2 \% från 16,2 \% (2) till $13 \%$ av den totala arbetstiden.

Kategorin Speciell omvårdnad utgjorde 4,9 \% av sjuksköterskans totala arbetstid. En av faktorerna för att framgångsrikt implementera PNV är att öka kompetensen hos vårdpersonalen. Genom kompetenshöjning skapas förutsättningar för dem att utföra flera specifika åtgärder och öka kontinuiteten genom att föra "den vårdande verksamheten" till patienten istället för tvärtom $(10,29)$. I jämförelse med delstudie 1 minskade tiden för Speciell omvårdnad med 2,7 \% från 7,6 \% (2) till 4,9\%. Det kan bero på en generell minskad andel av speciella åtgärder under observationsperioden men det kan också vara ett led i ökad effektivitet då flera prover kunde analyseras direkt av sjuksköterskan på respektive expedition.

I kategorin som utgjordes av Stöd, Information/Undervisning och Medverkan var andelen av sjuksköterskans totala arbetstid 7,6\%. Kategorin bestod av aktiviteter där kommunikation var den bärande enheten i mötet med patienten. Kommunikation med patienten förekom även i samband med att andra aktiviteter utfördes inne på patientrum men begränsades ofta av utförande av direkta praktiska vårdåtgärder. Den vunna tiden som sjuksköterskan får genom en implementering av PNV kan användas för att skapa möten med patienten. Möten som ökar förutsättningarna för att etablera en god vårdrelation och kommunikation mellan sjuksköterska och patient. Totalt sett är tiden för kommunikation inom den patientbundna tiden, även efter implementering av PNV, begränsad men ökade med 1,3\% i jämförelse med delstudie 1, från 6,3\% (2) till 7,6\%. Om sjuksköterskan har mindre tid till att etablera en vårdrelation med patienten kan det medföra att vården decimeras till enbart utförande av specifika vårdhandlingar, vilket kan påverka patientens välbefinnande. Implementering av PNV, på ett framgångsrikt sätt, innebär en ökad tillfredsställelse och delaktighet för patienten (14). Det handlar således inte enbart om att nya lokaler och fysiska positioner flyttas närmare patienten. PNV är en process, ett förändringsarbete som inbegriper alla individer $i$ verksamheten (14). Den kultur som finns på avdelningen och ett ledarskap som utgår från ett patientperspektiv samt ett sätt att formulera framtidens mål med patienten i fokus spelar en väsentlig roll för implementeringen av PNV (12). En målsättning med PNV är en ökad effektivitet med befintliga resurser, vilket kan uppfattas som att färre personer ska göra mer. Gemensamma mål kan öka förutsättningarna för en samstämmighet i verksamheten avseende betydelsen av att omfördela mer tid till patienten och göra denne mer delaktig.

\section{Metoddiskussion}

Den här studien har en icke experimentell kvantitativ ansats och resultatet har presenterats med beskrivande statistik. När studier genomförs före en förändring och efter, ökar studiens värde om det finns mer än två grupper som undersöks för att minimera faktorer som baseras på slumpen (21). Antalet avdelningar i studien bidrog till att ge ett så tillförlitligt resultat som möjligt, men när observationer genomförs ger det enbart en ögonblicksbild av verksamheten. Det finns en risk för att vårdtyngden och beläggning av platser inte är densamma vid olika tidpunkter. Det skulle därmed kunna påverka resultatet $i$ endera riktning. Därför är det mindre relevant med exakt tidtagning på sekundnivå, då många faktorer avgör, beroende på vilken typ av aktivitet som förekommer och vem som utför dem. Syftet med registrering av aktiviteter har således inte varit att tidsätta och optimera flöden för enstaka arbetsmoment. Ytterligare påverkansfaktorer som kan uppstå vid kontinuerliga observationer är att den observerade har kännedom om vad som ska observeras och på så sätt agerar på ett sätt som i sin tur kan påverka resultatet. Det är ett hot mot extern validitet (21). För att minimera denna faktor, informerade observatörerna sjuksköterskorna om studiens syfte men redovisade inte i detalj insamlingen av data eller hur lång tid ett visst arbetsmoment tog att utföra. På grund av upphovsrättsliga skäl var det inte möjligt att få tillgång till det instru- ment som använts vid delstudie 1. Det är en fördel och tillförlitligheten ökar om samma instrument kan användas (21). Tillförlitligheten i jämförelsen mellan studierna kan ändå anses säkerställd då båda instrumenten utgått ifrån VIPS-modellen (22). Instrumentet har validitets och reliabilitetstestats före start av observationerna. Kravet på ett instrument, som underlag för dokumentation av observationer, är tydliga definitioner av kategorier för vilka aktiviteter som avses observeras. Det är av vikt att inledande träning av instrumentet genomförs och därigenom säkerställa korrekt identifiering av kategorier för att öka reliabiliteten (21), vilket anses vara uppfyllt.

\section{SLUTSATS}

Den vunna tiden med PNV används inte i mötet med patienten inne på patientrum utan förläggs $i$ huvudsak till patientbundet arbete utanför patientrum. Att implementera PNV kräver mer än att utforma lokaler på ett bestämt sätt. Alla som arbetar i verksamheten bör ha målsättningen att planera och utföra sitt arbete hos patienten. För att sjuksköterskan ska vinna verklig tid med patienten inne på patientrummet och få till stånd ett möte, som kan lägga grunden för en god vårdrelation med ökad kommunikation med patienten, behövs det stöd från ledningen och gemensamma mål. Ledarna i verksamheten bör arbeta för att möjliggöra ett öppet klimat där idéer kan bli verklighet och verka för att kultur och värderingar i verksamheten utvecklas mot en ökad teamkänsla mellan alla professioner bortom hierarkier och traditioner. Patienten befinner sig längst ned i den hierarkiska pyramiden som präglar traditionell sjukvård. Utmaningen ligger i att vända på pyramiden och sätta patienten överst, först då kan patientens behov identifieras och tillgodoses.

\section{Tackord}

Tack till Alex Johansson för hjälp med observationer. Även stort tack till de sjuksköterskor som lät sig observeras i sitt arbete och därmed gjorde denna studie möjlig.

\section{Godkjent for publisering 25.02.14.}

${ }^{1}$ Carl Magnusson, RN, BScN, 2 Margaretha Ekebergh RN, Professor, ${ }^{2}$ Göran Jutengren, PhD in Psychology, ${ }^{2}$ Susanne Knutsson, RN, $\mathrm{BSc}$ in Nursing and Intensive Care, $\mathrm{PhD}$

${ }^{1}$ Ambulans- och Prehospital Akutsjukvård, Gullbergs Strandgata 36 C, SE - 41104 Göteborg

${ }^{2}$ Högskolan i Borås, Institutionen för vårdvetenskap, SE - 50190 Borås

Korrespondens till: Carl Magnusson. Telefon: +46 708 868620, carl.magnusson@vgregion.se

\section{REFERENSER}

1. Ekebergh M. Att lära sig vårda med hjälp av handledning: Lund: Studentlitteratur; 2009.

2. Carlsson W, Oscarsson I. Träffsäker vård ur patientens perspektiv med PNV. Södra Sveriges Sjuksköterskehem: Södra Sveriges Sjuksköterskehem, 2010.

3. Irwin RS, Richardson ND. Patient-focused care: using the right tools. Chest. 2006;130(1 Suppl):73S-82S.

4. Ho KMS. TQM and organizational change. International Journal of Organizational Analysis. 1999;7(2):169.

5. Kjornsberg A, Karlsson L, Babra A, Wadensten B. Registered Nurses' Opinions about Patient Focused Care. Australian Journal of Advanced Nursing, The. 2010;28(1):35-44.

6. Pitt C. Quality health care: identifying and meeting customer needs. International journal of health care quality assurance. 1993;6(6):25.

7. Moffitt GK, Daly PB, Tracey L, Galloway M, Tinstman TC. Patientfocused care: Key principles to restructuring. Hospital \& Health Services Administration. 1993;38(4):509.

8. Hurst K. The managerial and clinical implications of patient-focused care. Journal of management in medicine. 1996;10(3):59-77. 
9. Clouten K, Weber R. Patient-focused care ... playing to win. Nursing Management. 1994;25(2):34.

10. Inde M. Ännu närmre. För en god och säker patientnärmre vård. Karlstad: Landstinget Värmland; 2011.

11. Mang AL. Implementation strategies of patient-focused care. Hospital \& health services administration. 1995;40(3):426.

12. Nicholson J. Patient-focused care and its role in hospital process re-engineering. International Journal of Health Care Quality Assurance. 1995;8(7):23-6.

13. Myers SM. Patient-focused care: what managers should know. Nursing economic. 1998;16(4):180.

14. Jirsch D. Patient-Focused Care: The Systemic Implications of Change. Healthcare Management Forum. 1993;6(4):27-32.

15. Walker JK. Patient Satisfaction: The Past Directs the Way to the Future. The Journal of Perinatal \& Neonatal Nursing. 2006;20(1):88-90.

16. Reisdorfer JT. Building a Patient-Focused Care Unit. Nursing Management (Springhouse). 1996;27(10):38-45.

17. Seago JA. Evaluation of a Hospital Work Redesign: Patient-Focused Care. JONA: The Journal of Nursing Administration. 1999;29(11):31-8.

18. O'Dea CS. Patient-focused care: A descriptive study of RN satisfaction: ProQuest, UMI Dissertations Publishing; 1998.

19. Wiklund Gustin L. Vårdvetenskap i klinisk praxis. Stockholm: Natur och kultur; 2003.

20. Hendrich A, Chow MP, Skierczynski BA, Lu Z. A 36-hospital time and motion study: how do medical-surgical nurses spend their time? The Permanente journal. 2008;12(3):25.
21. Polit DF, Beck CT. Nursing research: generating and assessing evidence for nursing practice. Philadelphia: Wolters Kluwer Health/Lippincott Williams \& Wilkins; 2012.

22. Ehnfors M, Ehrenberg A, Thorell-Ekstrand I. VIPS-boken: om en forskningsbaserad modell för dokumentation av omvårdnad i patientjournalen. Stockholm: Vårdförb. SHSTF; 1998.

23. Lowry R. Analysis of Variance 2008 [cited 2012]. Available from: http://faculty.vassar.edu/lowry/VassarStats.html.

24. Körner S, Wahlgren L. Statistisk dataanalys. Lund: Studentlitteratur; 2006.

25. Rytterström $P$, Unosson $M$, Arman $M$. The significance of routines in nursing practice. Journal of Clinical Nursing. 2011;20(23 24):3513-22.

26. Jinks AM, Hope P. What do nurses do? An observational survey of the activities of nurses on acute surgical and rehabilitation wards. Journal of Nursing Management. 2000;8(5):273-9.

27. Williams H, Harris R, Turner-Stokes L. Work sampling: a quantitative analysis of nursing activity in a neuro-rehabilitation setting. Journal of Advanced Nursing. 2009;65(10):2097.

28. Myny D, Van Goubergen D, Limère V, Gobert M, Verhaeghe S, Defloor T. Determination of standard times of nursing activities based on a Nursing Minimum Dataset. Journal of advanced nursing. 2010;66(1):92-102.

29. Lathrop JP, Seufert GE, MacDonald RJ, Martin SB. The Patient-Focused Hospital: a patient care concept. Journal of the Society for Health Systems. 1991;3(2):33-50. 